\title{
Create painless community, create more happiness
}

Author/Photo: Yi Cheng, from the Oncology Department of Tongji Hospital, Tongji Medical College, Huazhong University of Science and Technology, Wuhan 430030, China

Received: 29 March 2010 / Revised: 5 April 2010 / Accepted: 15 April 2010

(c) Springer-Verlag Berlin Heidelberg 2010

On March 23rd, 2010, a ceremony was held in the Jiangbei branch of Hubei Xinhua Hospital, China. "The Standard Ward, Community Health Service Center, and Communities for Cancer Palliation and Analgesia Care in Hubei Province" were awarded in the ceremony. Professor Aihua Zang, the chairman of the Committee of Rehabilitation and Palliation Care, Hubei Province, China; Professor Yuanchao Tu, the president of Hubei Xinhua Hospital, China; Chief Liming Zhang, the director of Health Department of Jianghan District, Wuhan City, China and other experts were president in the ceremony.

The ceremony was hosted by Jianing Chen, vice President of Hubei Xinhua Hospital, China. Professor Zang introduced the achievements. In order to respond to the call "China is taking action in the World Analgesia Year", the committee launched the social activity "Painless Community" in February, 2009. This social activity was contributing to serving daily care for the patients suffering cancer pain. Seven groups were set up during the activity. These groups were responsible for 2 training seminars for more than 300 staff members in Hubei Xinhua Hospital,

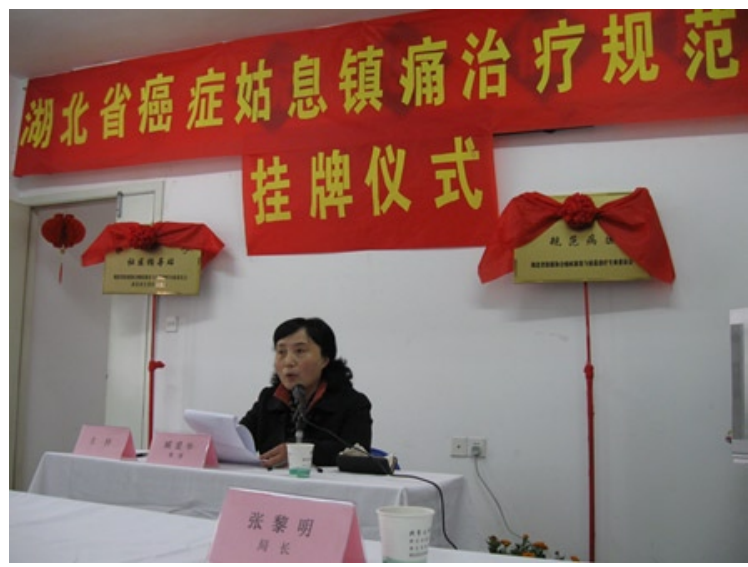

Professor Aihua Zang, the chairman of the Committee of Rehabilitation and Palliation Care, Hubei Province, China, was giving a speech

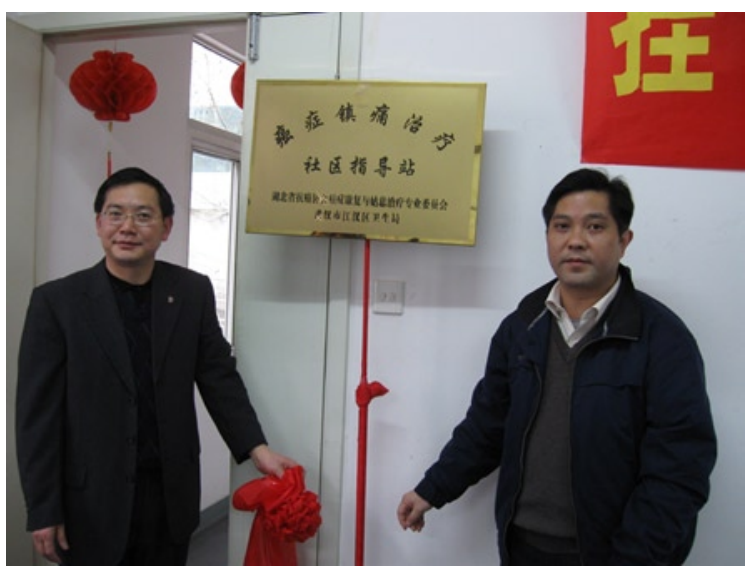

The Oncology Department, Hubei Xinhua Hosptial, China, was awarded "The Standard Community Health Service Center for Cancer Palliation and Analgesia Care in Hubei Province"

and public benefit activities in 7 communities in Jianghan District, including the propaganda and popularization for cancer pain care. The palliation care, the standard cancer pain care and the value and side effect of opioid drugs were emphasized in the social activity.

Professor Zang said: "We should highlight the importance of daily cancer pain care in communities and community hospitals, since it can improve the patients' life quality with the least cost. We can realize the painless dreams of patients suffering cancer pain, only if all the primary medical staff have the capacity and intention for palliation and analgesia care."

Then, Professor Tu and Chief Zhang introduced their works in the social activity.

The Oncology Department, Hubei Xinhua Hosptial, was awarded "The Standard Ward and Community Health Service Center for Cancer Palliation and Analgesia Care in Hubei Province". The Qianjin Street Community Health Service, the Wansong Street Community Health Service and the second Community Health Service of Hangxing Street were awarded "The Standard Community for Cancer Palliation and Analgesia Care in Hubei Province". 